\title{
Effective Instructional Leadership can Enhance Teachers' Motivation and Improve Students' Learning Outcomes
}

* Dr. Farah Naz, Assistant Professor (Corresponding Author)

** Surryia Rashid, PhD Scholar

\begin{abstract}
School principals as instructional leaders set clear goals, manage the instruction and curriculum, observe lesson plans, dispense resources and assess teachers consistently. They focus to improve the quality of teaching and aim to nurture student learning. The present study was conducted to investigate the impact of instructional leadership on teachers' motivation level and students learning outcomes at the secondary school. The research will create awareness among the instructional leaders that how important their actions are in making a conducive school. The research will create awareness among the instructional leaders that how important their actions are in making the school culture more effective and conducive. The sample size consisted of 400 teachers from public and private secondary schools. A questionnaire was used as a tool to collect data. The research was quantitative. A survey design was used to see the impact of instructional leadership on the teachers' motivation level and student achievement at the Secondary School Level. The questionnaire contained 35 items which were arranged into three factors, such as Instructional leadership, teacher motivation, and student learning. It was based on a five-point Likert scale. The findings of the research showed that both the male and female teachers of the public and private schools agreed that the instructional leaders encouraged teamwork developed positive relationships between parents and school staff. They agreed that the school principal tried to change the school climate according to the new trends.
\end{abstract}

Keywords: Instructional Leadership, Teachers' Motivation, Students' Learning Introduction

Leadership is the ability to raise others by utilizing their capabilities to achieve a goal. A leader is one or more people who deal with the diverse potential of the followers in such a way that they willingly and eagerly achieve the organization's mission and objective. The leader indulges in the process of strategic planning that encourages the followers toward the achievement of the organization's mission and objectives (Staub 2002).

Leadership is the ability to raise others by utilizing their capabilities to achieve a goal. A leader is one or more people who deal with the diverse potential of the followers in such a way that they willingly and eagerly achieve the organization's mission and objective. The leader indulges in the process of strategic planning that encourages the followers toward the achievement of the organization's mission and objectives (Staub, 2002).

The leader can achieve this influence through interpreting the future. By being proactive and futuristic, the leader can use intuition as well as critical thinking to foresee the future trends and then endeavor to bring about change and innovation in the current scenario according to those new trends. The role of the leader in this process was emphasized by Kark, Van Dijk, and Vashdi (2018), who displayed that efficacious leaders look at themselves as change envoys.

The word leader emanates from the Indo-European word 'leit'. Leading is about seeing and following one's vision which sets a course or example for others. Peter Drucker says: "The only definition of a leader is someone who has followers." A leader can transform the vision into reality and is keen to empower people. Leadership is a process of orchestrating the efforts of others for the accomplishment of goals. It's not about authority, power, and dominance. It's about maximizing effort toward a goal (Duşe, 2020). Leader with a clear vision follow the specific steps:

* Department of Education, University Management and Technology Lahore Email: farah.naz@umt.edu.pk

** Department of Education, University Management and Technology Lahore 


\section{Vision \\ (idea) \\ Communication \\ (word) \\ Empowerment \\ (action)}

A school is a place of instruction. It provides a formal learning environment for the students under the supervision of teachers. The goal is to build a strong bond between people and develop shared learning (Blase \& Blase, 2000). Shared decision-making has empowered the teachers and moved towards the professionalization of teaching. Instructional leadership in schools plays an important role in directing the curriculum and instructional programs. As an instructional leader, the school principals' facilitates learning, carry out the administration of the school, empower their team members and are willingly ready to share their skills, knowledge, and expertise with others (Bellibaş, Polatcan, \& K1lıç, 2020). They always focus on identifying the leadership skills in their subordinates and then allocate responsibilities according to their potential. They believe in distributing leadership among people and avoid the one-man show. Many players are involved in leading the people. The principals set the tone within the school. They promote learning not only by supervising the teacher but they operate more through the school culture by modeling themselves. They tend to become role models for the people in school instead of a traditional boss (Stewart, Astrove, Reeves, Crawford, \& Solimeo, 2017).

Instructional leaders perform myriad roles at the same time. They are managers, administrators, curricularists, teachers within one academy. To make the teaching-learning process smooth, they communicate goals to the people in the school, direct curriculum, observe and evaluate the lesson plans of teachers, assign resources efficiently and effectively. Productive instructional leaders are responsible for controlling the curriculum and instructional issues in schools that directly affect the student learning outcomes (Basu, Das, \& Chowdhury, 2015). The principal or instructional leaders are the most pivotal determinant for the brilliance of a school. The main role of the principal is to supply instructional leadership to the teachers by motivating them to perform their duties effectively and proficiently.

According to Basu et al. (2015), instructional leadership has a widespread idea; it elevates the scope of a principal and involves many other leaders in it as well. The main individuals in the instructional leadership include the directors, academicians, curricularists, principals, headteachers, assistant headteachers, coordinators, coaches, and mentors.

The work of instructional leaders is to make sure that they improve the quality of teaching which would lead towards the provision of the highest quality of instruction for the pupils thus resulting in required student learning. The principal design, implement, direct, lead and amalgamate all the programs with the unity that ultimately leads to the achievement of the goals within the educational institution (Shabani, 2016).

Teachers instruct and impart knowledge to others. They have great responsibilities in the education field. They are the beings who transform the pupils into positive human beings. Instructional leaders have a great impact in making the teachers feel valued or vice versa. Principals who create collaborative environments, support collective efficacy for teachers, and welcome parents in school are those who comprehend that how important their actions are to the school culture. Teachers and principals can both be leaders in schools, together in collaboration; they could lead to an inclusive environment that enhances the safety and continuous progress of the individuals within the school.

Effectual instructional leadership influences the students' learning results and consequences. It includes student's achievement, attendance, participation, academics activities, etc. indirectly and directly by expanding an environment that supports teachers' potential (Malloy \& Leithwood, 2017).

Instructional leaders aim at shared goals to create trust and commitment among people in school, whereas they continuously monitor the teaching-learning process so that they could develop their teachers and administrators professionally and not by just evaluating them. These leaders relentlessly work hard to explore and use the potential of their teachers which in turn make them assets for the school, students, and the whole community eventually (Perez \& McCorvey, 2020). 


\section{Literature Review}

The concept of instructional leadership became visible in the 1980s when an effective school movement began in the United States of America. It was an education reform that disclosed the crucial role of the principal in running the schools successfully. The research done through this movement discovered the ideal traits of principals (Pinder, 2017). The ideal principal showed determination, open-heartedness, and individuality. They plan effectively, communicate, display competency, work in collaboration, and are knowledgeable of content and pedagogy. As instructional leaders, the principals can initiate a work environment that is productive and conducive for teachers' motivation thus leading towards high yielding student outcomes (Bates \& Bailey, 2018).

Instructional leadership not only includes the principals as the key people for supervising the instruction of the school but they equally hold responsible other staff members for improving the atmosphere of the school. This tendency encourages the inclusive approach in instructional leadership. There is a collaborative relationship between principal and teacher to develop curriculum and instruction for the students at school. They both share the responsibility for improving the students' learning outcomes (Shaked, 2020).

The role of the principal takes into account the seven "P's" for leadership - People, Planning, Personality, Performance, Proficiencies, Purpose, and Persuasion and the seven "F's" of leadership focus, factual, fairness, flexible, friendly, fearless and futuristic (Belle, 2018). The principals should have an ambidextrous approach. They should create a balance between administrative matters and apply effective strategies to promote a healthy organizational climate and culture (Smyth, 2015). At the same time, they have multiple roles as trainer, adviser, and educator, and administer. They groom the talents of teachers and students, motivate them continuously and transform the school from a workplace to a learning place. The school principal is the foremost in charge of the school but instructional leaders do not concentrate the capacity of leadership in their hands only, on the other hand, they share the power among different people. They aim to make more leaders. They know that this is the work of not only one person. Instructional leadership becomes effective when it is shared and empowers other people. , the principals interact with teachers and endeavors to be dynamic and energetic by developing relevant curriculum, instructional activities, and materials that result in effective teacher-student learning (Pokharel, 2020).

Hallinger proposed 3 sides for the role of instructional leadership. They are planning the school's mission, directing the instructional activities, and establishing a positive school aura. The principal or instructional leaders are the most pivotal determinant for the brilliance of a school (Sebastian, Allensworth, Wiedermann, Hochbein, \& Cunningham, 2019). Instructional leadership has a widespread idea; it elevates the scope of a principal and involves many other leaders in this role (Smetana, 2020). It includes directors, academicians, curricularists, principals, headteachers, assistant headteachers, coordinators, coaches, and mentors. Effectual instructional leadership influences the students' learning results and consequences. It includes student's achievement, attendance, participation, academics activities etc. indirectly and directly by expanding an environment that support teachers' potential (Ringler, O'Neal, Rawls, \& Cumiskey, 2013)

The work of instructional leaders is to make sure that they improve the quality of teaching which would lead towards the provision of the highest quality of instruction for the pupils thus resulting in required student learning. The principal design, implement, direct, lead and amalgamate all the programs with the unity that ultimately leads to the achievement of the goals within the educational institution. Teachers instruct and impart knowledge to others. They have great responsibilities in the education field (Boston, Henrick, Gibbons, Berebitsky, \& Colby, 2017). They are the beings who transform the pupils into positive human beings. Instructional leaders have a great impact in making the teachers feel valued or vice versa. Principals who create collaborative environments, support collective efficacy for teachers, and welcome parents in school are those who comprehend that how important their actions are to the school culture(Bafadal, Nurabadi, Sobri, \& Gunawan, 2019).

Teachers and principals can both be leaders in schools, together in collaboration; they could lead to an inclusive environment that enhances the safety and continuous progress of the individuals within the school. The important components of teacher motivation are intrinsic motivation, extrinsic motivation, worldly motivation, and the eagerness for getting rid of negativity. Therefore, the 
principal as an instructional leader in school is responsible to instill all the above-mentioned segments in the teacher which would make them assets within the institution (Bafadal et al., 2019).

The school principals, as instructional leaders, revere the capabilities and knowledge of a teacher; they see them as wise and learned people and not just ordinary beings. Being the school leader, they should create an environment within the school that provides opportunities for both children and teachers to grow and learn. (Stukalina, 2014) established that the principal being an instructional leader is anxious to flourish the instructional dexterity of teachers, consequently resulting in valuable student achievement(Bafadal et al., 2019).

As instructional leaders, the principals can initiate a work environment that is productive and conducive for teachers' motivation thus leading towards high yielding student outcomes. To make the teaching-learning process smooth, they communicate goals to the people in the school, direct curriculum, observe and evaluate the lesson plans of teachers, assign resources efficiently and effectively. Productive instructional leaders are responsible for controlling the curriculum and instructional issues in schools that directly affects the student learning outcomes (Oti, 2018)

The responsibility of the school principal as an instructional leader is to encourage the teachers, school staff, students, parents, and other stakeholders in the educational domain to achieve the goals of the school. (Kort, 2008). Instructional leadership is regarded as a significant apparatus for running the schools effectively. They increase student achievement, attract and retain their strength to make them more effective in schools (Minton, 2020).

The research has been carried to investigate the traits of efficacious instructional leaders particularly the principals who motivate and groom the teachers by identifying their capabilities. They use their potentials in the best possible way which ultimately ameliorates the teacher-student learning consequences. The objective of the study is to inquire about the effect of instructional leadership on the teacher's motivation level that is closely related to elevated students learning outcomes. The focus was to find out the instructional leadership methodologies or styles that elevate teacher motivation and student learning outcomes in secondary schools (Romanowski, Sadiq, Abu-Tineh, Ndoye, \& Aql, 2020).

\section{Objective of the study}

The study aims to inquire about the effect of instructional leadership on the teacher's motivational level that is closely related to elevated students learning outcomes. The focus will hover around the secondary school level examining the relationship between principals and teachers that would affect the student learning outcomes.

\section{Research Questions}

1. What are the qualities of effective instructional leaders?

2. What is the impact of instructional leadership on teacher motivation and student learning outcomes at the secondary school level?

3. Will teacher motivation and student learning outcomes in secondary schools ameliorate or

\section{Methodology} improve with collaborative instructional leadership methodologies or styles?

The descriptive method of quantitative research design was used to see the impact of instructional leadership on teachers' motivational level and student achievement in secondary schools. The survey was conducted with the help of five points Likert scale questionnaire to examine the perceptions and attitudes of respondents about a research problem to test the hypothesis. The survey method is useful to adopt when the population is large in amount (Ishtiaq, 2019). A sample is the subset of the population. Four private and four government schools were selected through convenient sampling. The sample size of the study was 400 teachers of government and private secondary schools of the Lahore district. Four private boys' and girls' schools, two government boys' and two government girls' schools were selected. The respondents were the teachers of these schools. The sample size of the study was 400 teachers of secondary government and private schools of the district. The questionnaire contained 35 items which were further divided into three factors;

1. Instructional leadership

2. Teacher Motivation

3. Student Achievement 
The reliability of the questionnaire was calculated through Cronbach Alpha which was .961. Both descriptive and inferential statistics were used to analyze the data. All the data analysis was performed by using SPSS.

\section{Results}

Table1

Independent sample t-test comparing teachers' opinion based on gender

\begin{tabular}{lllllll}
\hline Factors & Gender & $\boldsymbol{N}$ & $\boldsymbol{M}$ & $\boldsymbol{S D}$ & $\boldsymbol{t}$ & $\boldsymbol{p}$ \\
\hline \multirow{2}{*}{ IL } & Male & 201 & 42.4776 & 8.66203 & -2.375 & .018 \\
& Female & 198 & 44.4848 & 8.20964 & -2.376 & .018 \\
Motivation & Male & 201 & 54.2687 & 10.41285 & -1.846 & .066 \\
& Female & 198 & 56.2424 & 10.94712 & -1.845 & .066 \\
\multirow{2}{*}{ Std. Achievements } & Male & 201 & 38.5174 & 7.76794 & -3.667 & .000 \\
& Female & 198 & 41.3990 & 7.92973 & -3.666 & .000 \\
\hline
\end{tabular}

A significant difference $(\mathrm{t}=-2.376, \mathrm{p}=.018)$ was found in the opinions of male $(\mathrm{M}=42.4776$,

$\mathrm{S} . \mathrm{D}=8.66203)$ and female $(\mathrm{M}=44.4848, \mathrm{~S} . \mathrm{D}=8.20964)$ teachers' opinion about instructional leadership. Regarding the factor of teacher motivation, the male teachers' opinion was $\mathrm{M}=54.2687$, $\mathrm{S} . \mathrm{D}=10.41285$, and female teachers' opinion was $\mathrm{M}=56.2424, \mathrm{~S} . \mathrm{D}=10.94712, \mathrm{t}=(-1.846), \mathrm{p}=.066$ which shows no significant difference between the mean ratings of the male and female teachers. Regarding the factor of student achievement, there is a difference $(\mathrm{t}=(-3.667), \mathrm{p}=.000)$ between the mean rating of perceptions of the male $(M=38.5174, S D=7.76794)$, and female $(M=41.3990$, $\mathrm{SD}=7.92973$ ).

Table 2

One Way Analysis of Variance based on age groups of teachers

\begin{tabular}{lllll}
\hline Factors & Gender & $\boldsymbol{M S}$ & $\boldsymbol{F}$ & $\boldsymbol{p}$ \\
\hline \multirow{2}{*}{ IL } & Between Groups & 275.981 & 3.859 & .022 \\
& Within Groups & 71.520 & & \\
Total & & & \\
Motivation & Between Groups & 428.459 & 3.758 & .024 \\
& Within Groups & 114.019 & & \\
Std. Achievements & Total & & & \\
& Between Groups & 218.801 & 3.463 & .032 \\
& Within Groups & 63.190 & & \\
\hline
\end{tabular}

A One-Way Analysis of Variance between groups was conducted to find out the difference of opinions among the teachers regarding the three factors in terms of their age. Three categories of age were used in the questionnaire. A significant difference was found among the opinions of teachers regarding the factor such as instructional leadership, teacher motivation and student learning in terms of the teachers' age. In this table, the significance level of these three factors was less than $.05, \mathrm{p}<.05$.

Table 3

One Way Analysis of Variance based on professional qualification of teachers

\begin{tabular}{lllll}
\hline Factors & Gender & $\boldsymbol{M S}$ & $\boldsymbol{F}$ & $\boldsymbol{p}$ \\
\hline \multirow{2}{*}{ IL } & Between Groups & 61.694 & .858 & .463 \\
& Within Groups & 71.937 & & \\
Total & & & \\
Motivation & Between Groups & 130.777 & 3.758 & .024 \\
& Within Groups & 114.188 & & \\
& Total & & & \\
Btd. Achievements & Between Groups & 37.129 & .589 & .623 \\
& Within Groups & 63.042 & & \\
\hline
\end{tabular}

Table 3.showed no significant difference among the opinions of teachers regarding the factors such as instructional leadership, teacher motivation, and student learning in terms of the teachers' professional qualification. Professional qualification was arranged in three categories. They were B.Ed., M.Ed., and others. In this table, the significance level of these three factors was more than .05, p>.05.

Table 4

One Way Analysis of Variance based on experience of teachers 


\begin{tabular}{lllll}
\hline Factors & Gender & $\boldsymbol{M S}$ & $\boldsymbol{F}$ & $\boldsymbol{p}$ \\
\hline \multirow{2}{*}{ IL } & Between Groups & 93.361 & 13.04 & .271 \\
& Within Groups & 71.320 & & \\
& Total & & & \\
Motivation & Between Groups & 58.303 & .523 & .593 \\
& Within Groups & 62.503 & & \\
& Total & 2.513 & .038 & .963 \\
Std. Achievements & Between Groups & 65.882 & & \\
& Within Groups & & & \\
\hline
\end{tabular}

Table 4.showed no significant difference among the opinions of teachers regarding the factors such as instructional leadership, teacher motivation, and student learning in terms of the teachers' experience. The experience of teachers was arranged into five categories. They were below $5 \mathrm{yr}, 5$ to $10 \mathrm{yr}, 10$ to $15 \mathrm{yr}, 15$ to $20 \mathrm{yr}$, and above $20 \mathrm{yr}$. In this table, the significance level of these three factors was more than $.05, \mathrm{p}>.05$.

\section{Hayes Process Model 4}

\begin{tabular}{|c|c|c|c|c|c|c|}
\hline \multirow[t]{2}{*}{ Predictor } & \multicolumn{3}{|l|}{ Motivation } & \multicolumn{3}{|c|}{ Student Learning } \\
\hline & Coefficient & SE & $P$ value & $\begin{array}{l}\text { Standardized } \\
\text { Beta }\end{array}$ & SE & $P$ value \\
\hline Constant & 5.3699 & 1.1735 & .000 & 4.4559 & 1.1329 & .0001 \\
\hline IL & .9082 & .0265 & .000 & .5312 & .0596 & .000 \\
\hline Motivation & - & - & - & .3364 & .0472 & .000 \\
\hline \multicolumn{7}{|l|}{ Controls } \\
\hline Gender & .0724 & & & & & \\
\hline Age & .0457 & & & & & \\
\hline Academic & -.0136 & & & & & \\
\hline \multicolumn{7}{|l|}{ Qualification } \\
\hline Experience & -.0431 & & & & & \\
\hline Professional & .0231 & & & & & \\
\hline \multirow{3}{*}{$\begin{array}{l}\text { Experience } \\
\text { Experience }\end{array}$} & & & & & & \\
\hline & & $\mathrm{R}^{2}=.825$ & & & $\mathrm{R}^{2}=.848$ & \\
\hline & $F(1,398)=1$ & $8, p<.001$ & & $F(2,397)=51$ & $4, p<.001$ & \\
\hline
\end{tabular}

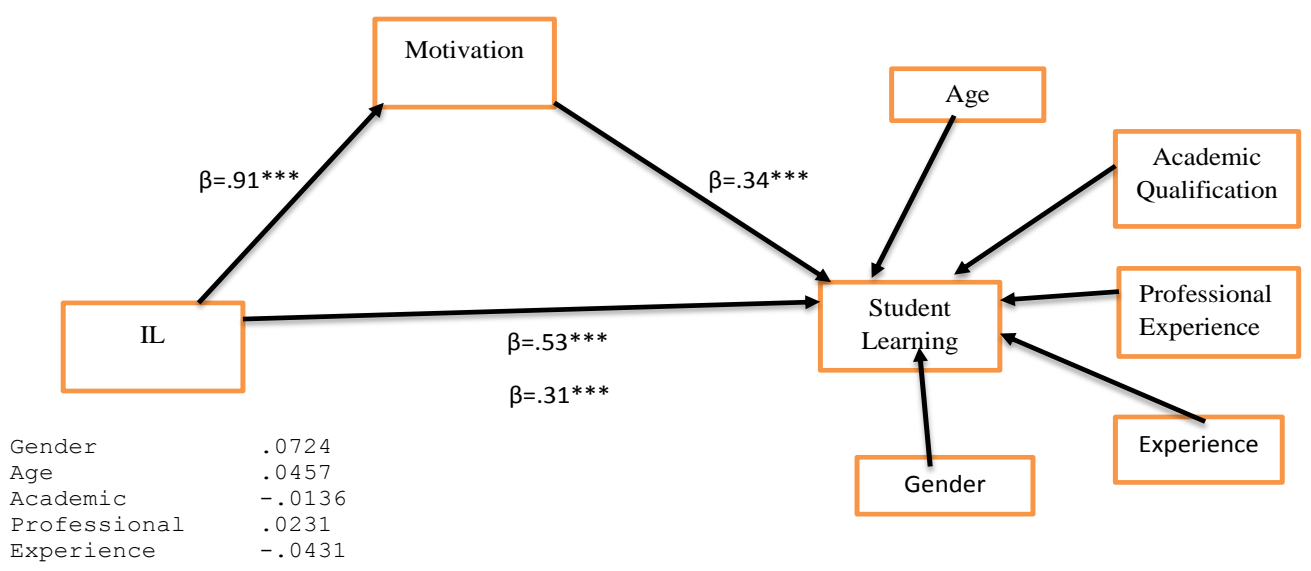

Hayes model was used with regression analysis to investigate the research question that instructional leadership mediates the effect of teacher motivation on student learning. Results indicated that instructional leadership was a significant predictor of teacher motivation, $\mathrm{B}=.9082$, $\mathrm{SE}=.0265, \mathrm{p}<.05$. It shows that instructional leadership has an indirect effect on student learning through teacher motivation. While instructional leadership directly affects student learning. 


\section{Finding and Discussions}

The research findings of the study indicated most of the teachers agreed that instructional leaders encouraged teamwork, endeavoured to change the school climate, fairly dealt with the school staff, and developed positive relationships between parents and school staff. They agreed that instructional leader acknowledges good work of the school staff; he/she has confidence in teacher's capabilities, raises the morale of teachers, trust in teachers' potential, and fosters respectful relationships between students and teachers. Hence, this attitude of the instructional leader raises the teacher's motivational level.

Most of the teachers agreed that instructional leadership significantly affects student learning outcomes. They agreed that instructional leaders ensure the participation of parents and teachers for better student outcomes. They arrange meetings with parents to discuss students' problems. They visit classes to improve the teaching strategies which are important for enhancing student learning. They work constantly with others and through others to improve the operations of the school affairs. However, most of the teachers gave a satisfactory response regarding instructional leaders' supervision and evaluation of instructional material as well as about provision of academic guidance to the teachers.

The instructional leaders were required to improve their role in these areas. They showed average responses regarding the involvement of staff members in the decision-making process. They also showed their reservations regarding the lack of professional development programs which are essential to improve the potential of teachers. Results showed that insufficient incentives were given for motivating the teachers to improve their performance. The instructional leaders made less effort in empowering the students which affected their leadership potential, which could in return affect the student learning outcomes as well. Most of the teachers showed average responses regarding the instructional leaders' provision of new teaching strategies and techniques used by the teachers in class.

A significant difference was found between the mean ratings of male and female teachers' opinions regarding instructional leadership and student outcome. This showed that in both the private schools and public schools, the teachers held different opinions about the instructional leaders' role in enhancing the student outcome. The instructional leaders needed to know their crucial part in making the teaching-learning process more conducive. The present research found that although the school leaders are endeavouring to run the operation of the schools they still needed to be more vigilant and support the school environment constantly. Their knowledge and management skill needs improvement. They should be able to inculcate better academic understanding among their teachers which would bring better student outcomes. They also need to evaluate the instructional materials more wisely in classes as it would help to improve the teachers' capability of teaching and reduce gaps in their teaching techniques.

While no significant difference was found between the mean ratings of the female and male teachers regarding teacher motivation. Most of the teachers responded that the instructional leaders acknowledged the good work of the teachers, supported the school staff, raised the morale of the teachers, and fostered a respectful relationship between teachers and students. This increased teacher motivation in schools and helped to retain the teachers for longer periods. It raised the sentiments of integrity and loyalty in teachers which is very important for a sound and stable school. There is no doubt that motivated teachers teach the students wholeheartedly. Believing in their potential makes them highly dedicated teachers who are always ready to teach their students with honesty. It also helps to create emotional stability between the teachers and students which is very vital for ameliorating student achievement.

A significant difference was found among the opinions of teachers regarding the factor such as instructional leadership, teacher motivation and student learning in terms of the teachers' age. No significant difference was found among the opinions of teachers regarding the factors such as instructional leadership, teacher motivation, and student learning in terms of the teachers' professional qualification. No significant difference was found among the opinions of teachers regarding the factors such as instructional leadership, teacher motivation, and student learning in terms of the teachers' experience. The results of the Hayes model 4 showed that instructional leadership directly affects the student learning outcomes through raising teacher motivation. Therefore, a healthy relationship between the instructional leaders and teachers would yield positive student outcomes. 
The leading aim of school principals as instructional leaders is ameliorating the teachinglearning process in their schools. The behavior of instructional leadership is very important for making the educational environment effective in schools. (Mannan, Sharma, Hoque, \& Veeriah, 2017) The school's instructional leader endorse effective instruction by keeping the educators wellinformed about novice educational strategies, technologies, and other methodologies for boosting the teaching-learning process in schools. (Sosibo \& Allie, 2017) put forward that instructional leaders develop such staff development programs which assure to increase the effectiveness of teachers which in turn would elevate the student outcomes. Being aggressive and innovative educationists, they keep conveying novel curricular and instructional materials to the educators.

Due to multitasking, the role of instructional leaders has become complex in today's era. It is not easy for the school leaders to be fully perfect in all the roles and functions they are responsible for running the school. Divergent challenges, shaky environmental changes, and globalization have increased the burden on the school leaders to a great extent. They encounter several problems while running the school affairs. High turnover of the teachers, non-cooperation of the teachers, implementation of new pedagogical techniques, teacher absenteeism, no clear vision, lack of professional training, limited motivation, bossy attitude are some of the grave challenges that have increased the stress level of the school leaders. Particularly, at the Secondary school level, the school leaders have to deal with the issues of managing student discipline. Mostly, at this level, the students complete their basic education. Therefore, instructional leaders are responsible to provide quality education at this level which is not an easy task at all...

Instructional leadership has a massive influence on the teaching-learning process in schools. They are responsible for ensuring successful student learning and growth. They aim at nurturing the vision of the school and expand the teachers' capabilities. They are active listeners, fair and consistent in their behavior. It must be kept in mind that it is the right kind of people and not the policies or rules that make up an effective school(DiPaola \& Wagner, 2018). It's awesome to have great teachers but if the school doesn't have a good principal then Good leaders grow themselves and give other people an opportunity to grow as well. Effective instructional leaders create an aura in their schools in which everyone feels valued and comes wholeheartedly (Reimers \& Chung, 2019).

\section{Conclusion}

The instructional leaders need to understand that the teachers in the school should be provided a comfortable environment in which they feel valued about their potential and abilities. The instructional leaders need to encourage the teachers constantly as it is the teacher who has to transfer the concept of knowledge to the students in the class eventually. In case, they are dissatisfied with the attitude or behavior of the instructional leader so how can one think that a teacher would give its best output in school. The dilemma is that most of the instructional leaders don't focus on the growth of their professional development. It is pertinent for the school leaders to grow themselves professionally, if they want outstanding student outcomes. They need to believe in life-time learning and then inculcate this sentiment in their teachers. In this way, the teachers would instill the attitude of never-ending learning in their students which would create more proactive and dynamic students in our society. It would strengthen the civic sense among the students and produce more responsible and wise citizens for our country.

\section{References}

Bafadal, I., Nurabadi, A., Sobri, A. Y., \& Gunawan, I. (2019). The Competence of Beginner Principals as Instructional Leaders in Primary Schools. International Journal of Innovation, Creativity, \& Change, 5(4), 625-639.

Basu, M., Das, P., \& Chowdhury, G. (2015). Introducing integrated teaching \& comparison with traditional teaching in undergraduate medical curriculum: A pilot study. Medical Journal of Dr. DY Patil University, 8(4), 431.

Bates, B., \& Bailey, A. (2018). Educational Leadership Simplified: A Guide for Existing \& Aspiring Leaders: SAGE.

Belle, L. J. (2018). The state secondary school principal as an effective leader of learner discipline management. British Journal of Education, 6(1), 43-54.

Bellibaş, M. Ş., Polatcan, M., \& Kilınç, A. Ç. (2020). Linking instructional leadership to teacher practices: The mediating effect of shared practice \& agency in learning effectiveness. Educational Management Administration \& Leadership, 1741143220945706. 
Blase, J., \& Blase, J. (2000). Effective instructional leadership: Teachers' perspectives on how principals promote teaching \& learning in schools. Journal of educational administration.

Boston, M. D., Henrick, E. C., Gibbons, L. K., Berebitsky, D., \& Colby, G. T. (2017). Investigating how to support principals as instructional leaders in mathematics. Journal of Research on Leadership Education, 12(3), 183-214.

DiPaola, M., \& Wagner, C. A. (2018). Improving instruction through supervision, evaluation, \& professional development: IAP.

Duşe, C.-S. (2020). TEACHERS AS LEADERS-A THEORETICAL APPROACH. Educația Plus, 26(1), 91-99.

Ishtiaq, M. (2019). Book Review Creswell, JW (2014). Research Design: Qualitative, Quantitative, \& Mixed Methods Approaches. Thousand Oaks, CA: Sage. English Language Teaching, 12(5), 40.

Kort, E. D. (2008). What, after all, is leadership?'Leadership'\& plural action. The Leadership Quarterly, 19(4), 409-425.

Malloy, J., \& Leithwood, K. (2017). Effects of distributed leadership on school academic press \& student achievement How school leaders contribute to student success (pp. 69-91): Springer.

Mannan, F., Sharma, S., Hoque, K. E., \& Veeriah, J. (2017). Predictive validity of gender \& experience of teachers into Malaysian women principal's instructional leadership practices. MOJEM: Malaysian Online Journal of Educational Management, 4(3), 52-67.

Minton, H. N. (2020). The relationship between superintendent leadership style \& district culture.

Oti, D. (2018). Instructional leadership roles of headteachers on the performance of teachers in six selected public Junior High Schools in Buoho circuit in the Afigya Kwabre district. The University of Education. Winneba.

Pinder, G. T. (2017). The Effectiveness of Pre-Service Principal Preparation Programs on Instructional School Leadership in High-Stakes Testing Grades: Seton Hall University.

Pokharel, B. (2020). PRINCIPALS FOR SCHOOL CHANGE: A STUDY OF INSTITUTIONAL SCHOOLS OF NEPAL: Cook Communication.

Reimers, F. M., \& Chung, C. K. (2019). Teaching \& learning for the twenty-first century: Educational goals, policies, \& curricula from six nations: Harvard Education Press.

Ringler, M. C., O'Neal, D., Rawls, J., \& Cumiskey, S. (2013). The Role of School Leaders in Teacher Leadership Development. Rural Educator, 35(1), n1.

Romanowski, M. H., Sadiq, H., Abu-Tineh, A. M., Ndoye, A., \& Aql, M. (2020). Principal selection for Qatar's government schools: Policy makers', principals' \& teachers' perspectives. Educational management administration \& leadership, 48(5), 893-915.

Perez, J., \& McCorvey, J. (2020). Using Data Collection Tools to Enhance University Supervisors' Socially Just Teaching Practice.

Sebastian, J., Allensworth, E., Wiedermann, W., Hochbein, C., \& Cunningham, M. (2019). Principal leadership \& school performance: An examination of instructional leadership \& organizational management. Leadership \& policy in schools, 18(4), 591-613.

Shaked, H. (2020). Social justice leadership, instructional leadership, \& the goals of schooling. International Journal Of Educational Management.

Smetana, A. L. (2020). Transformative Responsiveness \& School Leadership: A mixed-method approach toward closing academic achievement gaps.

Smyth, G. (2015). Ambidextrous leadership: The perfect balance that leads to great leadership. Leadership Excellence Essentials, 32(2), 29.

Sosibo, Z., \& Allie, F. (2017). Influence of school principals' leadership styles on the effectiveness of lowincome Cape Town schools. Journal of Educational Studies, 16(1), 87-107.

Staub, R. E. (2002). The heart of leadership: 12 practices of courageous leaders, BookBaby.

Stukalina, Y. (2014). Identifying predictors of student satisfaction student motivation in the framework of assuring quality in the delivery of higher education services. Business, management, \& education, 12(1), 127.

Kark, R., Van Dijk, D., \& Vashdi, D. R. (2018). Motivated or demotivated to be creative: The role of selfregulatory focus in transformational \& transactional leadership processes. Applied Psychology, 67(1), 186-224. 